\title{
Identification of empirical relationships between indices of ENSO and NAO and agricultural yields in Spain
}

\author{
Luis Gimeno $^{1, *}{ }^{,}$Pedro Ribera ${ }^{1}$, Raquel Iglesias ${ }^{1}$, Laura de la Torre ${ }^{1}$, \\ Ricardo García ${ }^{2}$, Emiliano Hernández ${ }^{2}$ \\ ${ }^{1}$ Universidad de Vigo, Facultad de Ciencias de Orense, 32004 Orense, Spain \\ ${ }^{2}$ Universidad Complutense, Facultad de Ciencias Físicas, Ciudad Universitaria, 28040 Madrid, Spain
}

\begin{abstract}
This study characterizes the influence of the El Niño-Southern Oscillation (ENSO) and the North Atlantic Oscillation (NAO) on the most important crops in Spain using statistical analysis of the response of historical yields to ENSO and NAO phases. The response to ENSO phases is weak, being only significant for lemon yields, whereas the response to NAO phases is stronger, being significant for lemon, wheat, rye and olive. The results could be useful for producers, allowing them to adjust crop management, and for politicians, allowing better quantification of national crops limits.
\end{abstract}

KEY WORDS: Agriculture $\cdot$ Spain $\cdot$ NAO $\cdot$ ENSO

Resale or republication not permitted without written consent of the publisher

\section{INTRODUCTION}

Climate is one of the major factors which directly or indirectly influences the space-time distribution of most agricultural systems. Such agricultural systems will therefore be vulnerable to interannual climate variability, with regard to both extreme events and changes in the traditional patterns of regional climate (Hoogenboom 2000).

As research into interannual climate variability and short-term climate prediction has been progressing steadily, there is increasing interest in applying shortterm climate forecasts to crop management (Ogallo et al. 2000). The background of these forecasts is the El Niño-Southern Oscillation (ENSO). For instance, Nicholls (1985) suggested a close relationship between the ENSO and Australian crop yields, and Cane et al. (1994) used the Pacific sea-surface temperature (SST) to forecast maize yields in Zimbabwe. Although these 2 examples refer to regions close to the location of the ENSO occurrence, its effects can be felt around much of the globe (Kiladis \& Diaz 1989, Bell et al. 1999). The ENSO accounts for a substantial proportion of the

*E-mail: 1.gimeno@uvigo.es observed interannual variability of temperatures and precipitation in the extratropics, so the influence on agricultural must be also present. Hansen et al. (1999) found that the ENSO influences winter vegetables in Florida, while similar influences were found by Hsieh et al. (1999) for Canadian prairie wheat yields and by Izaurralde et al. (1999) for crop productivity in North America.

Fewer studies have been performed in Europe and consequently in Spain, due to the fact that the ENSO signals are weak. However, Bell et al. (1999) showed that during El Niño events atmospheric fluxes are more zonal, precipitation higher and winter temperatures milder than in normal years in southern Europe. During La Niña episodes precipitation is lower than normal especially in southwestern Europe and northern Africa. These results seem also to be present in other historical periods (Gimeno et al. 1998).

The dominant mode of interannual variability in most of Europe is associated with the North Atlantic Oscillation (NAO). The influences of the NAO on Spanish regional climate and consequently on its agricultural yield are more consistent than the effects of ENSO. So, when NAO is in its positive phase, there is warm weather over Europe, as well as wet conditions 

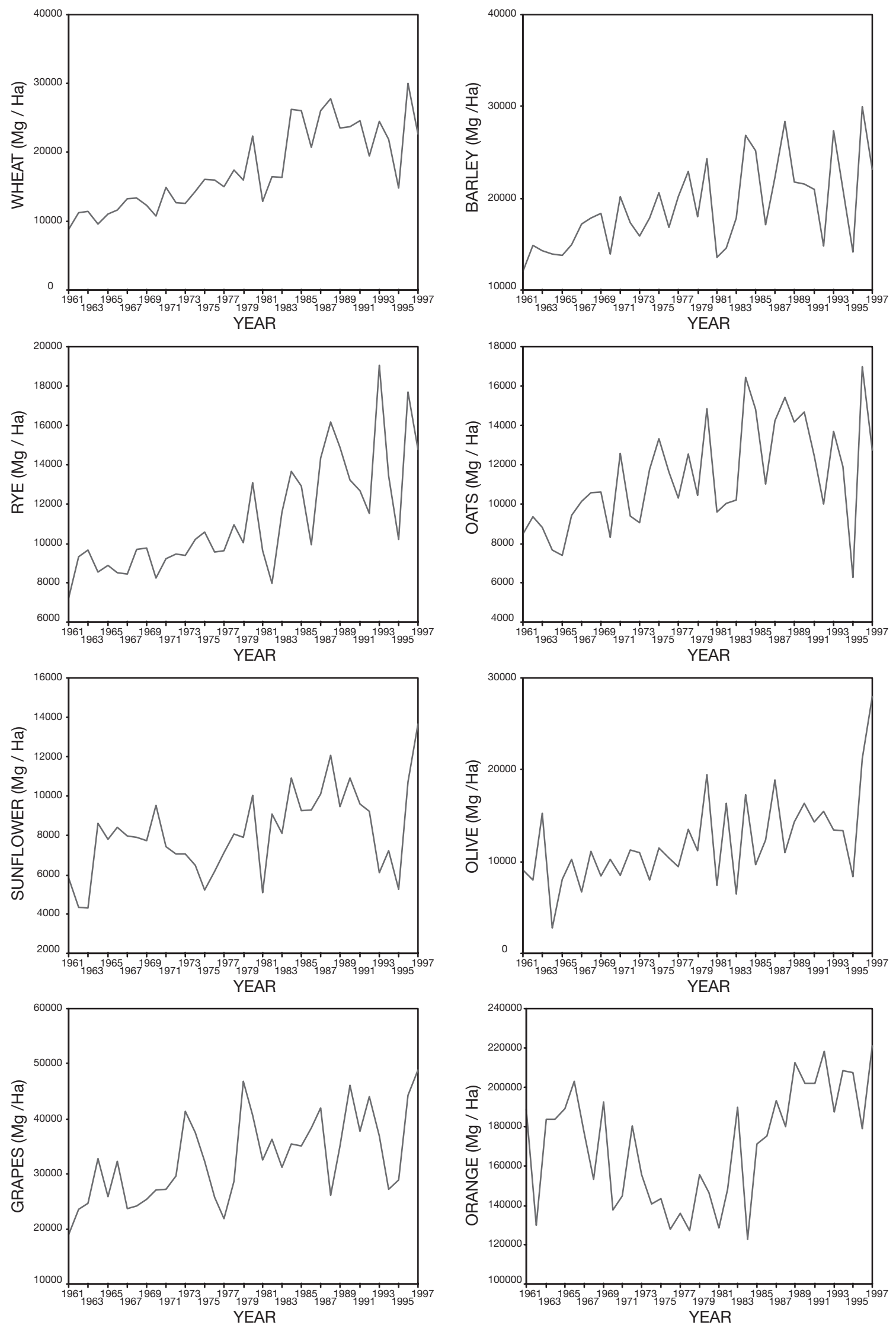

Fig. 1. (Above and facing page.) Analyzed crop yields evolution (1961-1997) 

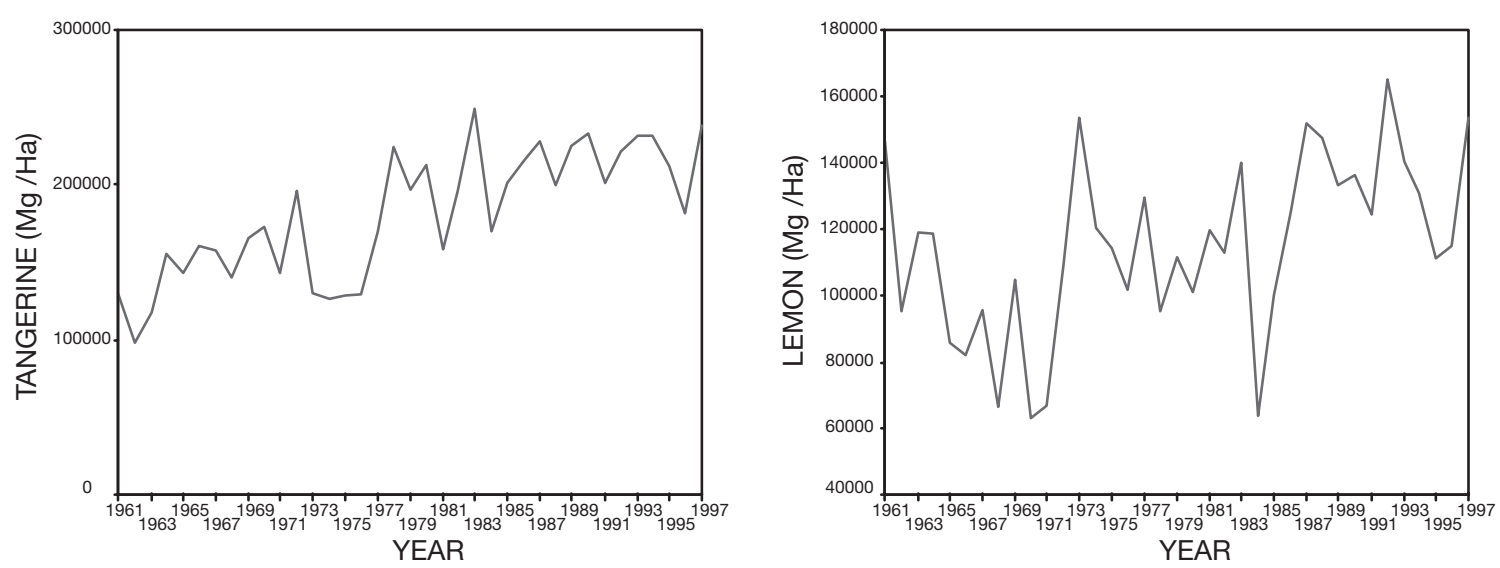

Fig. 1 (continued)

from Iceland through Scandinavia and dry conditions over southern Europe (Hurrell 1996, Hurrell \& Van Loon 1997). Through these effects on climatic conditions, the NAO should influence agricultural systems in western Europe. To know the meteorological process responsible for the connection between the NAO or the ENSO and crop yields is a very difficult task and outside the scope of this paper. The objective here is to identify empirical relationships between the ENSO and the NAO events and yields and prices of the most significant agricultural crops in Spain.

\section{MATERIALS AND METHODS}

The approach used in this study was to identify associations between annual values of crop yields with the ENSO and NAO phases from historical records (19611997).

\subsection{Classification of ENSO phases}

The classification of ENSO phases made by the Center for Ocean-Atmospheric Prediction Studies (COAPS; available at www.coaps.fsu.edu/) was used. This classification is based on a 5 mo running mean of SST anomalies, spatially averaged over the tropical Pacific from 90 to $50^{\circ} \mathrm{W}$ and from $4^{\circ} \mathrm{N}$ to $4^{\circ} \mathrm{S}$. A year is classified as being in the El Niño phase when SST anomalies are bigger than $0.5^{\circ} \mathrm{C}$ for at least 6 consecutive months. In the case where SST anomalies are below $-0.5^{\circ} \mathrm{C}$, the year is considered as being in the La Niña phase. Otherwise it is considered a neutral year. The analysed period included 9 El Niño (1964, 1966, 1970, 1973, 1983, 1987, 1988, 1992 and 1997) and 7 La Niña $(1965,1968,1971,1972,1974,1976$ and 1989) events. In the analysis we also used the Southern Oscillation Index (SO index), defined as the mean value of the difference between the normalized sealevel pressure over Darwin (Australia) and Tahiti for a whole year. It was taken from the Climatic Research Unit of the University of East Anglia (UK) (www.cru. uea.ac.uk).

\subsection{Classification of NAO phases}

The NAO index was used to identify NAO phases. It was defined as the mean value of the difference between the normalized sea-level pressure over the Azores and Iceland during the standard winter months (December, January and February). This winter value is presumed to characterize the whole year beginning that January. Like the SO index it was taken from www.cru.uea.ac.uk. To quantify negative and positive phases of the NAO, we used the average of the index for the period plus/minus multiples of the standard deviation. So the analyzed period includes 8 positive phases $(1963,1977,1985,1986,1991,1992,1994$ and $1997)$ and 5 negative phases $(1965,1967,1971,1979$, and 1981).

\subsection{Crops}

The database for the agricultural yield was extracted from the Food and Agricultural Organization (FAO) database (www.fao.org/ag/guides/resource/data.htm). There is 1 entry $\mathrm{yr}^{-1}$ for each crop that corresponds to the yields $\left(\mathrm{Mg} \mathrm{ha}^{-1}\right)$ for the civil year (yield in the year in which most crop was harvested). The analyzed crops were cereals (wheat, barley, rye and oats), sunflower seed, olives, grapes and citrus fruits (orange, tangerine and lemon). Fig. 1 shows observed crop yields. To avoid long-term trends due to changes or improvements in management practices, the series were linearly detrended. 


\subsection{Method}

Two alternative methods of analysis were used. First an ANOVA analysis was made to identify differences between the harvest yields for the different crops in El Niño, La Niña and neutral years, and in positive and negative NAO years. Then the cross-correlation functions (CCF) between every crop time series and the NAO and SO indices' time series were evaluated to detect significant correlations. Furthermore, to avoid spurious effects in the previous correlations, a BoxJenkins methodology was applied to pre-whiten the time series. When done, the CCFs were re-evaluated to detect significant correlations not due to co-temporality. A schematic of this methodology is displayed in Fig. 2.

\section{RESULTS}

Box plots showing 0, 25, 50, 75 and 100th percentiles of harvest for the 3 ENSO phases are displayed in Fig. 3. From a single view we can observe that ENSO seems to have more influence on fruits than on cereals when considering mean yields. The differences during the 3 ENSO phases are very low for cereals, but higher for fruits. In general terms harvests were lower during La Niña phase. This happened in 8 of the 10 crops analyzed. Harvest variability was also higher during El

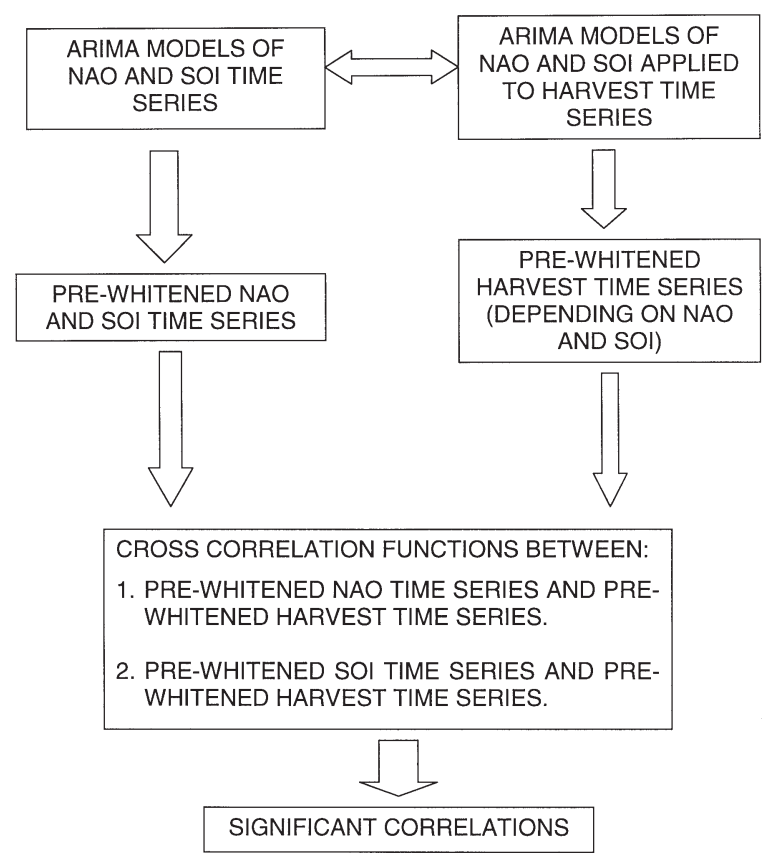

Fig. 2. Box-Jenkins methodology used to pre-whiten the time series
Niño years than during La Niña years. These preliminary results are in agreement with the reported ENSO effects on regional climate. Precipitation in Spain is lower than average during La Niña events, although this signal is neither strong nor consistent.

In Fig. 4 box plots of harvests are shown for the neutral, negative and positive phases of the NAO. A positive or negative phase is defined as a year when the NAO index is higher or lower, respectively, than the 37 yr average by at least 1 SD. 0, 25, 50, 75 and 100th percentiles are also displayed. In general terms cereal yield dispersion is higher for the NAO positive phase than for the NAO negative phase. This happened for 3 out of the 4 crops analyzed. For sunflower seeds the median was almost the same for the 2 phases, though with a much bigger dispersion for the positive phase. Citric yields are bigger for the positive NAO phase.

These preliminary influences of ENSO and NAO phases on crops were tested by ANOVA (Steel \& Torrie 1980). Duncan's multiple range test identified which ENSO or NAO phases differed significantly $(\mathrm{p}<$ 0.05 ) in their effects on a crop (Table 1). For the ENSO phases, significant differences were only found for sunflower. Sunflower yield is significantly higher for El Niño years than for La Niña years. For NAO phases, significant differences were found for lemon (Table 1). Its mean yield was significantly higher for years catalogued as NAO positive phases than for years catalogued as NAO negative phases.

When cross-correlation analysis between crops and the NAO and ENSO indices was made, we found only 1 common result with ANOVA analysis, namely the influence of NAO on lemon yield. Table 1 shows those lags with significant correlations $(95 \%)$. For lag $=0$ (same year), significant negative correlations existed between orange and tangerine and the SOI. Lag values indicate the number of years that NAO or ENSO preceded the shift in crop yields.

Since we are mostly interested in studying the influence of ENSO and NAO in later crops, we will only analyze the relationships for positive lags that remain significant after the application of Box-Jenkins methodology. Wheat, orange and lemon are the only crops that fulfil these conditions. Wheat yield is positively correlated with NAO index with a 1 yr lag, and so are orange and lemon yields with lag $=-1$. NAO dominates the temperature and pluviometry of the year that begins during the winter for which we define the index. So, wheat yield is directly related to those conditions. On the other hand, orange and lemon yields are collected during the last months of the year. This fact explains why their relationship with the meteorological situation is most significant during those months. By definition we can see that NAO index for one year is calculated from data for January and Feb- 

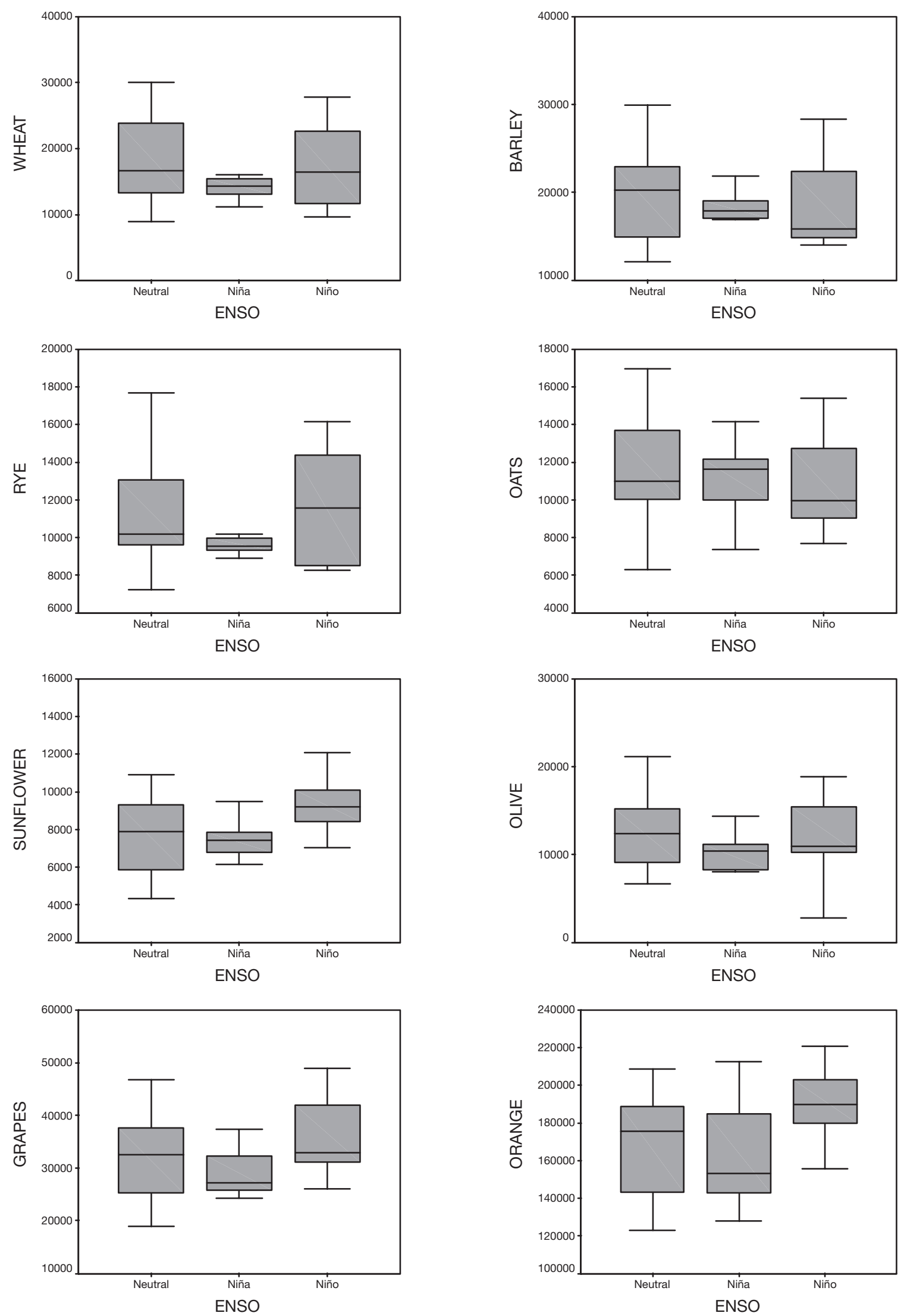

Fig. 3. (Above and following page.) Box plots showing 0, 25, 50 (solid line), 75 and 100th percentiles of crop yields by ENSO phase. $\mathrm{N}=21,7$, and 9 for Neutral, La Niña, and El Niño, respectively 

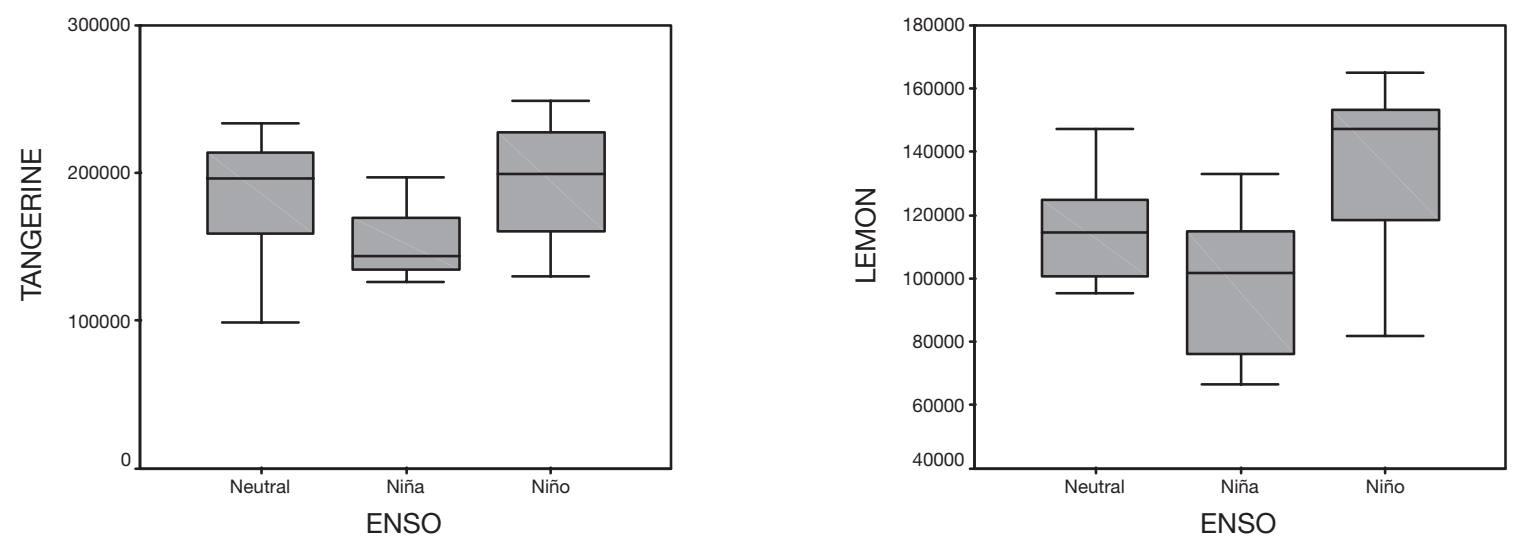

Fig. 3 (continued)

ruary of that same year and from December of the previous year, and it is during those months when part of the yield is collected. Finally, the ENSO index shows negative correlations with orange and tangerine productions for lag $=0$.

To evaluate the possible influence of ENSO and NAO on the price of the crops that showed significant correlations in Table 1, an economic valuation was per-

Table 1. Significant correlations between harvest and NAO or SOI time series. Numbers in bold are the lags (in years) between NAO or SOI and the harvest. Pearson correlation coefficients are given in parentheses. ${ }^{*}$ Correlations that remained significant after pre-whitening (Box-Jenkins methodology). Shaded cells show those crops with significantly different mean yields under 1-factor ANOVA tests $(\mathrm{p}<0.05)$

\begin{tabular}{|lcc|}
\hline & NAO & ENSO \\
\hline Wheat & $\mathbf{1}(0.34)^{*}$ & $\mathbf{2}(-0.35)$ \\
Rye & & $\mathbf{2}(-0.38)$ \\
Sunflower & & $\mathbf{0}(-0.36)$ \\
Olive & & $\mathbf{0}(-0.43)^{*}$ \\
Orange & $\mathbf{- 1}(0.38)^{*}$ & $\mathbf{0}(-0.57)^{*}$ \\
Tangerine & $\mathbf{- 1}(0.39)$ & $\mathbf{1}(-0.35)$ \\
Lemon & $\mathbf{- 1}(0.49)^{*}$ & \\
& $\mathbf{2}(0.37)$ & \\
\hline
\end{tabular}

formed. The price trends of wheat, orange, lemon and tangerine were extracted from the FAO database. To obtain a homogeneous series, new values were estimated with price differences from one year to the next divided by the price of the first year. The new series represents the rates of price variation from one year to the next as a percentage. In Table 2 the influence of NAO and ENSO on these prices is presented. To account for the time effect, NAO and ENSO influences were evaluated working with the lags observed after applying Box-Jenkins pre-whitening.

The NAO influence is most evident in respect to the price of wheat. A very high increase is visible the year after a positive NAO episode, while after negative episodes and neutral years the increments are very low. On the other hand, lemon prices are sensitive to both positive and negative NAO episodes. A decline in the lemon prices is observed in the year previous to a severe episode of NAO, while in neutral years there is a tendency toward higher prices. Orange prices do not seem to be significantly dependent on the NAO phase.

ENSO influence on crop prices was studied for orange and tangerine. Though not very strong, this influence is higher for tangerine prices, which show a price increment of $8.4 \%$ in the El Niño years, while in neutral or La Niña years the price increment is lower (approx. 2\%). Variations of orange prices are low for every phase, being a little bit higher for El Niño years than for the other years.

Table 2. Mean price variations of crops (\%) from one year to the next for positive, negative and neutral phases of NAO and ENSO. The second and sixth columns indicate the lag for which the variations where estimated $(+: \operatorname{lag}=1 ;-: \operatorname{lag}=-1 ;=: \operatorname{lag}=0)$

\begin{tabular}{|c|c|c|c|c|c|c|c|c|}
\hline & & Positive & $\begin{array}{c}\text { NAO } \\
\text { Negative }\end{array}$ & Neutral & & Positive & $\begin{array}{c}\text { ENSO } \\
\text { Negative }\end{array}$ & Neutral \\
\hline Wheat & + & 32.4 & 1.5 & 0.0 & & & & \\
\hline Orange & - & 5.7 & 10.3 & 4.3 & $=$ & 3.2 & 2.4 & 1.4 \\
\hline Lemon & - & -9.3 & -19.8 & 12.3 & & & & \\
\hline Tangerine & & & & & $=$ & 8.4 & 1.7 & 1.9 \\
\hline
\end{tabular}



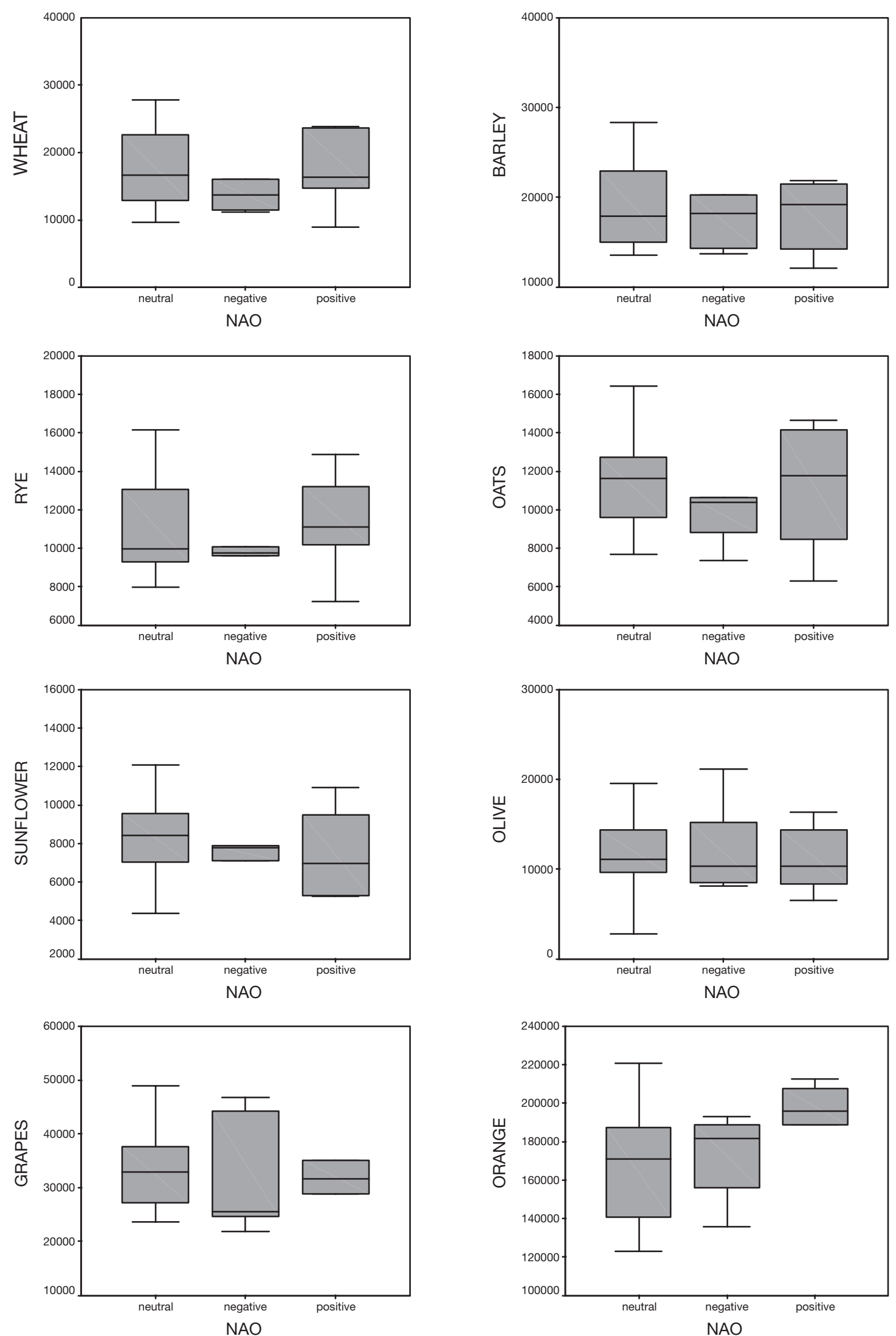

Fig. 4. (Above and following page.) Box plots showing 0, 25, 50 (solid line), 75 and 100th percentiles of crop yields by NAO phase. $\mathrm{N}=24,8$, and 5 for neutral, negative, and positive, respectively 


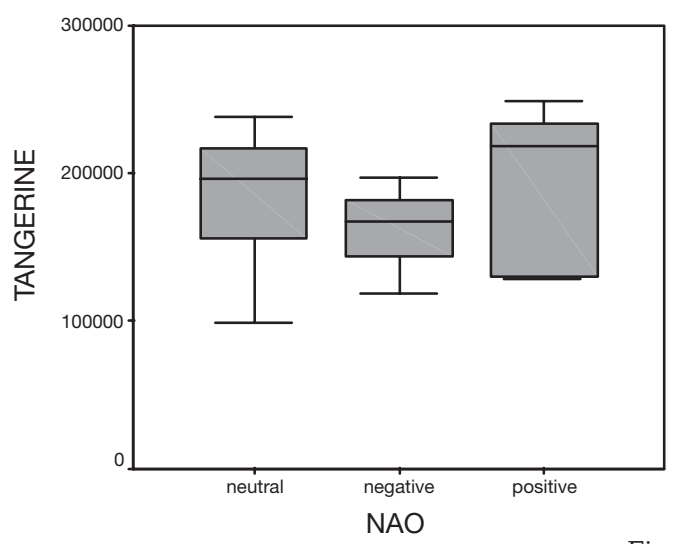

Fig. 4 (continued)

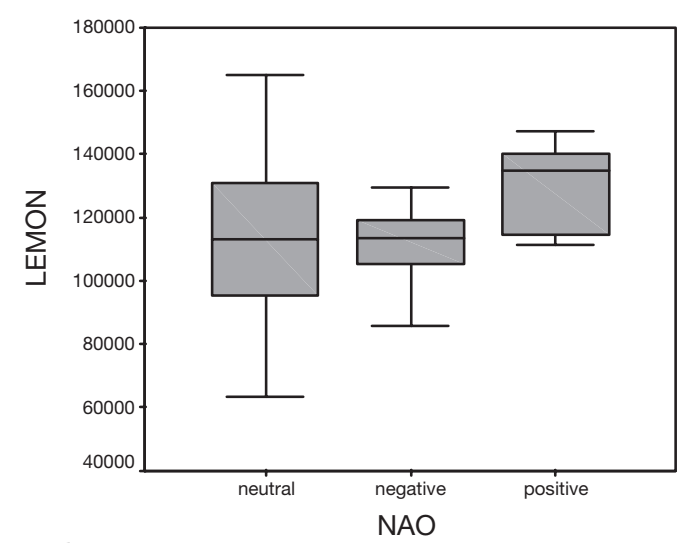

\section{CONCLUSIONS}

This study characterizes the empirical influence of El Niño-Southern Oscillation (ENSO) and the North Atlantic Oscillation (NAO) on the most important Spanish crops. Statistical tests could detect an effect on yield for several crops. Orange and tangerine yields are the crops most influenced by variations in the ENSO, while wheat, orange and lemon are affected by the NAO evolution.

Wheat, barley, rye, sunflower, olive, grapes and tangerine are more likely to exhibit low yields during La Niña years than during El Niño years. When considering the NAO influence, wheat, rye, oats and citrus yields show higher yields during positive NAO phases than during negative ones.

Results from this study could have important implications for producers and politicians. Due to the fact that the last El Niño was successfully forecasted 6 mo before its commencement, producers of tangerine and orange could have applied seasonal predictions to adjust crop management or to take advantage of higher prices. Even more important for Spanish producers are the effects of the NAO on crops, especially on wheat and lemon, for which variations in prices depending on the NAO phase have been observed. The European Commission decides on the ceiling on production for many crops for those countries belonging to the European Union. A substantial percentage of the decision is arrived at on the basis of the average yield in preceding years. Our work points to the fact that the influence of climate variability factors such as NAO and ENSO must also be taken into account in such decisions. However, these results are preliminary and require further research to identify the driving meteorological factors, and they should be handled with care.
Acknowledgements. We would like to thank the anonymous reviewers for the advice they gave.

\section{LITERATURE CITED}

Bell GD, Halpert MS, Ropelewski CF, Kousky VE, Douglas AV, Schnell RC, Gelman ME (1999) Climate assessment for 1998. Bull Am Meteorol Soc 80(5):S1-S48

Cane MA, Eshel G, Buckland R (1994) Forecasting Zimbabwean maize yield using eastern Pacific sea surface temperature. Nature 370:204-205

Gimeno L, García R, Hernández E (1998) Precipitations in the Canary Islands in the Seventeenth Century and its relationship with El Niño events. Bull Am Meteorol Soc 79: 89-91

Hansen JJ, Jones JW, Kiker CF, Hodges AW (1999) El NiñoSouthern Oscillation impacts on winter vegetables production in Florida. J Clim 12:92-102

Hoogenboom G (2000) Contribution of agrometeorology to the simulation of crop production and its applications. Agric For Meteorol 103:137-157

Hsieh WW, Tang B, Garnett ER (1999) Teleconnections between Pacific sea surface temperatures and Canadian prairie wheat yield. Agric For Meteorol 96:209-217

Hurrell JW (1996) Influence of variations in extratropical wintertime teleconnections on Northern Hemisphere temperatures. Geophys Res Lett 23:665-668

Hurrell JW, Van Loon H (1997) Decadal variations in climate associated with the North Atlantic Oscillation. Clim Change 36:301-326

Izaurralde RC, Rosenberg nJ, Brown RA, Legler DM, Tiscareño M, Srinivasan R (1999) Modeled effects of moderate and strong 'Los Niños' on crop productivity in North America. Agric For Meteorol 94:259-268

Kiladis GN, Diaz HF (1989) Global climatic anomalies associated with extremes in the Southern Oscillation. J Clim 2:1069-1090

Nicholls N (1985) Impact of the Southern Oscillation on Australian crops. J Climatol 5:553-560

Ogallo LA, Boulahya MS, Keane T (2000) Applications of seasonal to interannual climate prediction in agricultural planning and operations. Agric For Meteorol 103:159-166

Steel RGD, Torrie JH (1980) Principles and procedures of statistics: a biometrical approach, 2nd edn. McGraw-Hill, New York

Submitted: August 7, 2000; Accepted: December 3, 2001

Proofs received from author(s): June 6, 2002 